\title{
Study on Application of Micro Class Teaching Model in College English Teaching
}

\author{
$\mathrm{Na} \mathrm{Liu}$ \\ Tianshi College China Tianjin 301700
}

Keywords: Micro class; Internet; education reform; College English teaching; Classroom efficiency

\begin{abstract}
The micro class is an innovative teaching model derived from the Internet and the educational reform and development. At present, the micro class has been widely used in College English teaching, and has opened up a new model of College English teaching, and has achieved good teaching results. However, in the application of the micro class, the situation still exists in the form, which affects the teaching efficiency of the University pronunciation. In this paper, the author mainly studies the problems and misunderstandings existing in the current micro class mode in College English teaching, and puts forward some suggestions on how to use the micro class reasonably and improve the efficiency and quality of College English teaching.

As a new type of teaching mode, the micro class has provided many conveniences for the classroom teaching of College English after the elaborate design of information teaching. With the wide application of micro class, it has become an important way for college students to learn independently. There are some differences with the traditional teaching mode. Micro class only changes the way of presentation and transmission of learning content, but it does not change the properties of the content. From practice teaching, it can be seen that some English teachers lack the correct understanding of the micro class, and as a new teaching mode, there are inevitably some mistakes in teaching, which affect the teaching efficiency. Based on this, the author has studied the effective application of micro class teaching model in College English classroom.
\end{abstract}

\section{Part One A summary of the Micro Class}

\section{The Meaning of the Micro Class}

Micro class is a new learning resource which is provided by the Internet technology to students with video and audio as the carrier. Specifically, the micro course is based on the idea of teaching design, according to the different teaching contents and methods making the production of PPT courseware, short video taped editing mode. Usually, the time of the micro class will be controlled around 5-15 minutes. It is an important way for students to study independently and cultivate their interest in learning.

\section{Characteristics of Micro Class}

The characteristics of the micro class are summarized as the following three points:

Firstly, the content of the micro class is more prominent. Different from the traditional classroom teaching mode, micro class is aimed at a certain link or key difficulty of the teaching content. Therefore, the content and theme of the micro class are more prominent and have certain pertinence.

Secondly, compared with the traditional teaching mode, the micro class is more diversified. Before the application of micro class, we need to record audio or video in advance, and display it to students in diversified forms according to actual teaching needs, so as to stimulate students' interest. In the process of making micro class, teachers can also intersperses pictures, words and even music to mobilize the enthusiasm of students, and help students concentrate on learning in a short time, so as to improve the efficiency of classroom.

Finally, the time of the micro class is more free, and the students can choose the time to study according to their own circumstances. The content of the micro class is short and refined, and it is easy to store. Through mobile phones, computers and so on, students can learn and watch videos anytime and anywhere. So the time of the micro class is more free and convenient and flexible.

As the micro class has more advantages than the traditional teaching mode, under the 
background of rapid development of education reform, micro class has become an important way to improve teaching efficiency and stimulate students' interest in learning, and it is also the mainstream trend of classroom teaching development.

\section{Part Two The Common Problems in College English Classroom Teaching}

\section{Lack of Understanding of the Model of Micro Class}

In recent years, micro class has become an important auxiliary way of College English teaching. However, there are still some teachers' deviations in the understanding of micro lesson. Even some teachers recognize that micro lesson is a small course, which is a slicing of traditional classroom teaching mode. Therefore, in the design of micro class, teachers still adopt the traditional teaching methods and process, which leads to the long design of the micro class. From a large number of practical teaching experience, it is found that the time of the micro class is 5-8 minutes. Some people think that the application of the micro - class has taken the place of the teacher's role to some extent. Because through micro class, students can learn all knowledge, weaken the role of teachers in class, and some teachers think that micro class is a condensed classroom, even as a way to detect students' learning efficiency. In short, for the micro class, different teachers have many different understandings, and there will be some wrong understanding, which affects the efficiency of the micro class teaching. The role of teachers in classroom is self-evident. If teachers can't correctly understand the importance of micro class, they can't play the role of micro class in College English teaching, so the teaching effect is very difficult to achieve the desired goal.

\section{The Improper Selection of the Subject of Micro Class Influences the Design of Teaching}

The content of the micro class should be concise and easy to understand, and to highlight the key and difficult problems, so the topic is a very important link. In practical teaching, because of teachers' lack of knowledge and lack of experience, it is easy to have problems of improper selection of topics, which will affect the design of teaching. For example, the content of teaching is too simple, there is no in-depth explanation, or much teaching activities are designed, but neglecting the substantial content, which leads students to learn valuable things after watching micro lessons. In terms of instructional design, some teachers try to achieve multiple teaching objectives through micro lectures, resulting in higher knowledge density. Students do not know where the key is after watching micro lectures. In addition, the design of some micro classes neglects the problem of students' thinking which makes the design of the micro class flow in the form. The most prominent feature of the micro class should be that the orientation of the target should be accurate, which can help students to absorb knowledge more effectively.

\section{The Quality of Micro Class Production is not High}

For some college English teachers, it is difficult to make high quality micro video. Although most teachers have some basic computer technology, but because it is not professional, so the level is limited, there are defects in the video and the production inevitably, such as a video clip is not clear, clip is not reasonable and lack of subtitles which will affect the enthusiasm of the students.

\section{Students Lack the Ability to Learn Autonomously}

Autonomous learning is the learning behavior of the student's self - management and self Evaluation, and the students' ability to self-control is higher. Therefore, the students' autonomous learning ability will affect the smooth progress of the micro class to a certain extent. Many students lack the ability of independent students. They can not preview and study the micro class according to the requirements of the teachers before class, which leads to the low efficiency in the classroom. Some studies also show that it is difficult for students to conduct an important reason that there is no independent learning motivation, and the micro class is mainly on grammar, words and sentences, the lack of leading questions and thinking, there is no difference with the traditional classroom teaching, and students are not interested on it. 


\section{Part Three Suggestions and Measures for the Effective Use of Micro Class in College English Teaching}

\section{Change the Concept of Micro Class Teaching}

The micro class itself is a new type of teaching mode, so in order to improve the application efficiency of the micro class, teachers should change the teaching concept. In the course of long term teaching, English teachers will accumulate teaching experience and the way of teaching. Teachers should integrate these teaching feelings and ideas into the teaching process, and then combine the actual needs of the students to constantly update the teaching concept and keep pace with the times. To integrate micro teaching into classroom, teachers need to correctly understand the meaning of micro class, and know that micro teaching is no longer the traditional teacher explaining teaching, but a complete subversion and upgrading of traditional teaching. Teachers should not inculcate knowledge blindly, so as to embody the subject status of the students. In class, we should encourage students to ask questions and express their opinions and ideas. We should not measure students with right or wrong, evaluate students, arouse students' enthusiasm, and promote harmonious and friendly relationship between teachers and students. In addition to changing the traditional classroom mode, teachers should also guide students to think and understand problems through design problems, reflection and discussion, so as to achieve the best results in classroom teaching.

The selection of the Content of the Micro Class should be Valuable to Meet the Needs of the Students at Different Levels

The content of the micro class is the key to improve the efficiency of the classroom. In the process of production, teachers should further study the content of teaching materials, divide the key points and difficulties, ensure the content of micro class selection is valuable, and effectively use the micro class for 5-8 minutes. At the same time, teachers should adjust the teaching arrangements properly to ensure that students of different levels and abilities have knowledge from the micro class. The valuable content should reflect the difficulties and core problems of teaching, so as to solve the problems quickly, explain the problems and reflect the efficiency of the micro class. Before making micro class, teachers should understand students' needs according to teaching content requirements, students' psychological characteristics and learning ability, so that we can arrange key points and difficulties reasonably. In addition, the teaching strategy to have the flexibility to meet the students' cognitive ability, should also strengthen the micro interactive course, guide students to think about the problem or appropriate to add some interesting things in the appropriate link, stimulate the students' interest and desire for knowledge. In the teaching link, the teacher's language should be infective. This kind of micro class can make the students highly concentrated and improve the learning efficiency.

In order to cultivate students' autonomous learning ability, teachers can encourage students to find information, think and solve problems independently, so as to improve their English level in the process of learning. In addition, teachers should actively guide students when they are needed.

\section{It is Very Important for Students to Improve Their Autonomous Learning Ability}

In the process of using micro class teaching, teachers should also attach importance to the cultivation of students' self-learning ability and strengthen the efficiency of micro class teaching. English is different from other subjects. Learning English well requires not only listening to teachers' sentences, structures, grammar and so on, but also doing exercises after class, so as to consolidate knowledge and internalize it. Therefore, it is necessary for college students to have a strong independent academic ability. Teachers can guide students to use the network platform to learn, but to avoid students addicted to the network, and to teach their own experience to students. In the course of learning, teachers should give students more encouragement and praise and exercise their students' self-learning ability, rather than let students rely on teachers. Based on mastering computer technology, students can study independently by micro class, there is an advantage that can repeatedly watch, for emphasis or do not understand the question, students can repeatedly pondering to ask teachers, so as to cultivate the spirit of exploration. In the process of autonomous learning, students will gradually form their own learning methods. With the help of 
micro class video learning, students' learning ability will significantly improve, which will play a positive role in the smooth development of subsequent classroom teaching.

\section{Conclusion}

To sum up, the development and application of micro class teaching completely subverts the traditional classroom model, and points out a new direction for the development of education reform. As a college English teacher, we should have a correct understanding of the importance of micro class in English teaching process, encourage students to use self-learning, explore problems and cultivate independent learning ability. At the same time, in the production of micro class, teachers should further study the content of teaching materials, and embody the difficult knowledge and core problems in the micro lesson, and we should pay attention to the value of selected content. Only in this way can we play the role of the micro class, guide the students to think, cultivate the interest in English, and finally achieve the purpose of improving the efficiency of the class.

\section{Reference}

[1] Bing Li, Ping Wang. A study on the teaching mode of "flipped class" in College English based on micro class[J].Modern Communication,2016,(13):11-12.

[2] Shaochun Zhong, Zhuo Zhang, Huawei Tang. Thinking on the key problems in the design and application of micro courses[J].China Electronic Education,2014,(12):85-88.

[3] Jia Liang, Wenjun Lu. A brief discussion on the application of micro class in the University of Applied Technology[J].Commerce, 2016( 4):218.

[4] Xiaobin Zheng. Research on the problems and Countermeasures of micro class teaching in Higher Vocational Colleges[J].Journal of Lanzhou Institute of Education, 2015(3):88 - 90. 